\title{
QUALIDADE AMBIENTAL DO MUNICÍPIO DE IMPERATRIZ-MA: UMA ANÁLISE MULTICRITÉRIO DE INDICADORES INTRA-URBANOS
}

\author{
Rodrigo Lima Santos \\ Bolsista CAPES, Doutorando em Geografia \\ Instituto de Estudos Socioambientais IESA - UFG \\ rlimasantos3@gmail.com \\ Fabrizia Gioppo Nunes \\ Universidade Federal de Goiás - UFG \\ Professora do Instituto de Estudos Socioambientais - IESA \\ fabrizia.iesa.ufg@gmail.com \\ Alex Mota dos Santos \\ Universidade Federal de Goiás - UFG \\ Professor da Faculdade de Ciências e Tecnologia - FCT \\ alexmota@ufg.br
}

\begin{abstract}
RESUMO
Este estudo tem por objetivo avaliar a qualidade ambiental da cidade de Imperatriz-MA utilizando-se de abordagens integrativas de dados do meio físico-estrutural e censitários. Para a confecção da carta de qualidade ambiental, consideraram-se os-indicadores relacionados à carência da oferta de serviços públicos essenciais como os de saneamento básico; densidade demográfica; grau de urbanização e verticalização das edificações; dificuldade da mobilidade urbana; escassez ou ausência de vegetação arbórea e arbustiva e de espaços públicos de lazer; além de fatores geomorfológicos como áreas de riscos a inundações e alagamentos. A metodologia incluiu levantamento bibliográfico, utilização de dados censitários, bem como de dados primários oriundos do processamento digital de imagens de sensoriamento remoto. A carta síntese de qualidade ambiental urbana foi realizada por meio da Análise Multicritério, via combinação por somatória das variáveis que representam indicadores negativos, ou seja, daqueles desfavoráveis à qualidade ambiental. O município de Imperatriz apresentou valores que a posicionam em uma faixa de qualidade ambiental intermediária, englobando o equivalente a $78,37 \%$ de seu perímetro urbano mapeado. Neste cenário, conclui-se que, quanto mais próximo do núcleo urbano, a qualidade ambiental é mais precária, devido à maior somatória de variáreis negativas encontradas nestas regiões de bairros mais antigos da cidade.
\end{abstract}

Palavras-chave: Mapeamento. Gestão Urbana. Bem-estar Social.

\section{ENVIRONMENTAL QUALITY OF IMPERATRIZ MUNICIPALITY IN MARANHÃO STATE/BRAZIL: A MULTICRITERIAL ANALYSIS OF INTRA-URBAN INDICATORS}

\begin{abstract}
This study aims to assess the environmental quality of the city of Imperatriz-MA, using integrative approaches to data from the physical-structural and census media. To prepare the environmental quality It was considered aspects related to the lack of essential public services such as basic sanitation; demographic density, degree of urbanization and verticalization of buildings; difficulty of urban mobility, represented by traffic flow; scarcity or absence of tree and shrub vegetation and public leisure spaces; in addition to geomorphological factors such as flooding and flooding risk areas. The methodology includes bibliographic survey, use of census data, as well as primary data from the digital processing of remote sensing images. The synthesis map of urban environmental quality were performed through Multicriteria Analysis by the summation of the variables that represent negative indicators, that is, those unfavorable to environmental quality. The municipality of Imperatriz presented indexes point to values that position the municipality in an intermediate environmental quality range, encompassing the equivalent of $78.37 \%$ of the mapped area. In this scenario concluded that the closer to the urban core, the environmental quality is more precarious, due to the greater sum of negative variables found in these regions the oldest neighborhoods in the city.
\end{abstract}

Keywords: Mapping. Urban management. Social welfare.

$\begin{array}{lllll}\text { Caminhos de Geografia } \quad \text { Uberlândia-MG } & \text { v. 21, n. } 78 \quad \text { Dez/2020 } & \text { p. 01-20 Página }\end{array}$




\section{INTRODUÇÃO}

Um dos principais tópicos alusivos à gestão da qualidade de vida urbana é a verificação da qualidade ambiental, por intermédio de indicadores intra-urbanos. Tal premissa pode ser confirmada no campo conceitual, pois, de acordo com Nahas (2009, p.126), quando se trata da utilização de indicadores ambientais, direcionados à governança urbana, "a qualidade ambiental no sentido estrito, se torna um dos elementos do dimensionamento da qualidade de vida urbana". Desta forma, diversos são os autores que têm se dedicado a essa abordagem, pois a qualidade ambiental prioriza a adequabilidade dos ambientes urbanos na vida de seus habitantes (BUCCHERI FILHO e TONETTI, 2011).

Nesse ínterim, Tonetti (2011), fundamentado nos modelos teóricos apresentados por Kamp et al. (2003) e nos estudos realizados por Nucci (2008), atrela o "conceito de qualidade ambiental urbana como parte de um conceito muito mais abrangente que é o conceito de qualidade de vida". Para o autor, a qualidade ambiental urbana é compreendida através das condições favoráveis do ambiente urbano, "ou seja, dos aspectos físicos, químicos e biológicos do local de estudo que suprem as necessidades fisiológicas e psicológicas do ser humano" (TONETTI, 2011, p. 37). Entretanto, alguns fatores demonstrativos da relação sociedade $x$ natureza ainda precisam ser melhores definidos, pois estes podem lidar com fenômenos mensuráveis e não mensuráveis.

Embora os dados censitários disponibilizados pelo Instituto Brasileiro de Geografia e Estatística (IBGE) sejam mensuráveis e, cada vez mais, utilizados como indicadores da qualidade de vida das cidades brasileiras, o valor da paisagem urbana ainda é difícil de ser estimado e sua avaliação depende, em parte, de experiência subjetiva (DELSANTE, 2016). Porém, com o avanço das geotecnologias, muitos dos elementos relacionados com a qualidade da paisagem urbana são quantificáveis e passíveis de serem expressos diretamente ou convertidos através do processo de ponderação, em valores numéricos, em ambiente de Sistema de Informação Geográfica (SIG). Assim, destaca-se que os SIGs são ferramentas de análise, que tem suas bases científicas sustentadas pela Teoria Geral dos Sistemas, Geodésia, Lógica Matemática, Geoestatística, dentre outras abordagens do conhecimento científico.

No caso do gerenciamento urbano, por tomada de decisão em SIG, um dos métodos mais usuais é a análise multicritério, proveniente do acrônimo em inglês GIS based Multicriteria Decision Analysis (GIS-MCDA). Essa, por sua vez, pode ser definida como o conjunto de ferramentas computacionais que utilizam algoritmos matemáticos para representar e combinar diferentes variáveis. Sua importância advém do fato de que os problemas de decisão espacial normalmente envolvem um grande conjunto de alternativas viáveis e de critérios de avaliação múltiplos, conflitantes e incomensuráveis (MALCZEWSKI, 2006). Neste sentido, Santos et al. (2012) explicam que uma das principais técnicas da análise multicritério é a combinação ponderada, onde as variáveis são normalizadas em uma escala de pesos. Desta forma, é identificada a importância das variáveis para cada dimensão, onde os resultados serão utilizados em contextos reais de aconselhamento ou tomada de decisão (CINELLI et al., 2014).

Neste contexto, a avaliação da adequação do uso e cobertura da terra, utilizando a Análise Multicritério, em ambientes urbanos, deve ser similar à escolha de locais apropriados, que integrem vários pontos de vista das partes interessadas, oferecendo as melhores alternativas na elaboração de um índice de adequação para todos os segmentos a serem mapeados (JOERIN et al., 2001). Como ferramentas de análise espacial, os SIGs permitem a integração de diferentes critérios, enquanto a Análise Multicritério pode ser usada para agrupá-los em um índice de adequação, frente aos diferentes tipos de ocupação e suas respectivas implicações.

Dessa maneira, os elementos que compõem o espaço urbano e os fenômenos que nele ocorre são passíveis de serem mapeados (NUCCl, 1998), e sua distribuição espacial pode revelar áreas dotadas de menor ou maior qualidade ambiental (RODRIGUES, 1997; NUCCI, 2008; LANG e BLASCHKE, 2009). Neste viés, muitos trabalhos têm caracterizado e avaliado, por diferentes metodologias e ainda utilizando diferentes critérios, a qualidade ambiental em distintas cidades brasileiras, cabendo destacar: Bezerra (2008); Nucci (2008); Buccheri Filho e Tonetti (2011); Valaski (2013); Ferreira 
(2015); Tonetti et al. (2018), em especial nas regiões Sul e Sudeste do Brasil. No entanto, essas publicações ainda são incipientes em verificar as correspondências da qualidade ambiental auferida com outros aspectos da realidade objetiva das cidades. Assim sendo, este trabalho se justifica pela escassez de análises mais aprofundadas da qualidade dos espaços urbanos, contexto no qual o município de Imperatriz-MA se insere. Elege-se como problemática o fato de que a ocupação do meio físico não observa tem observado as diretrizes municipais, desse modo identificou-se diversos impactos ambientais.

Fundamentado nesta premissa, o objetivo deste trabalho foi avaliar a qualidade ambiental da cidade de Imperatriz - MA, utilizando-se de uma abordagem que integra tanto dados do meio físico-estrutural da cidade quanto dados censitários. Além disso, examinou-se o comportamento da qualidade ambiental em função dos períodos de surgimento da malha urbana, uma vez que a paisagem revela também as facetas do passado no tempo presente (CARLOS, 2008). Deste modo, procurou-se evidenciar, neste artigo, que a qualidade ambiental de uma cidade, em vista de sua trajetória de ocupação, pode revelar as heterogeneidades denotadas pela paisagem do sítio urbano em conformidade com sua conjuntura atual.

Dentre as variáveis utilizadas para mensurar a qualidade ambiental da paisagem de Imperatriz estão a cobertura vegetal; áreas de risco as inundações e alagamentos; a densidade demográfica; verticalização das edificações; o grau de urbanização; as vias com fluxo de trânsito elevado; espaços públicos de lazer; e as variáveis censitárias das condições de saneamento. As reflexões basearam-se tanto na análise espacial individual das variáveis, quanto na utilização do método de análise multicritério apresentado por Carver (1991), que resultou no mapa de qualidade ambiental urbana da cidade, adaptado da proposta de Nucci $(1998 ; 2008 ; 2010)$.

\section{FUNDAMENTAÇÃO TEÓRICA}

Neste artigo, defende-se que uma das teorias que sustenta os estudos da qualidade ambiental via Análise Multicritério é a abordagem sistêmica, ou de maneira formalizada, também denominada de Teoria Geral do Sistemas. Essa teoria foi proposta por Ludwig Von Bertalanffy, biólogo alemão, em 1937, que de modo geral é considerada como a precursora da biologia teórica. Este novo paradigma científico desencadeou mudanças fundamentais na compreensão do mundo, de forma dinâmica e integrada (BERTALANFFY, 1972).

Contudo, segundo Weckowicz (2000), as contribuições dessa teoria foram além da biologia e estenderam-se à psicologia, psiquiatria, sociologia, cibernética, história e filosofia. Na geografia, a discussão sobre a abordagem sistêmica é pormenorizada por Vicente e Perez Filho (2003). Para os autores, "trata-se do próprio delineamento de uma proposta de cunho multidisciplinar que transcende o ambiente físico-químico ou sócio-cultural stricto sensu" (VICENTE e PEREZ FILHO, 2003, p. 331). Além disso, busca a complexidade do ambiente percebido pelo homem como o verdadeiro espaço para a necessária interação entre aplicação/compreensão. Ainda segundo os autores, o desdobramento desse conceito nas ciências da natureza sustenta as discussões em ecologia, que estabelece o conceito de ecossistema. Na geomorfologia, subsidia a teoria do ciclo de erosão, e, na biogeografia, resgata as quatro escalas biogeográficas, dentre outras (VICENTE e PEREZ FILHO, 2003).

Dessa abordagem, por opção metodológica, o sistema pode ser subdividido em partes, mesmo sabendo-se que, segundo essa teoria, a totalidade representa mais do que a soma de todas as partes. Assim, a sua operacionalização revela que o mais importante é a ideia do conjunto de elementos interligados para formar um todo, que possua propriedades e características próprias, que não são encontradas em nenhum dos elementos isolados. Em diversas ocasiões, essa perspectiva se integra à ideia dos Sistemas de Informação Geográfica, que operam no campo metodológico e servem a tomadas de decisão por multicritérios.

Os métodos de decisão por multicritérios (Multi-criteria decision analysis - MCDA) tiveram suas primeiras aplicações no início dos anos 1970 (CARVER, 1991). Via de regra, esses métodos preocupam-se com a análise, cruzamento e integração de dados geográficos para oferecerem

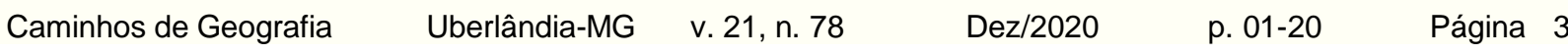


possibilidades de decisões (CARVER, 1991; JOERIN et al., 2001; KIKER et al. 2005; MENDOZA e MARTINS, 2006; WALLENIUS et al. 2008). Foram concebidos em oposição aos métodos tradicionais de análise por sobreposições cartográficas. E podem ser considerados como a representação operacional das variáveis de um sistema em seu estado ambiental, econômico ou social. Alguns exemplos são os indicadores da pressão antrópica e os indicadores nacionais desenvolvidos pela Organização das Nações Unidas para o Desenvolvimento Sustentável - ONU (GASPARATOS et al., 2008).

Huang et al. (2011) revelam as possíveis razões pelas quais os MCDA estão ganhando atenção em diferentes aplicações. Em especial, a utilização desse tipo de método para aplicações ambientais ocorre nos continentes Europeu e Asiático, enquanto, na América do Sul, o número de trabalhos ainda é incipiente. À vista disso, Malczewski (2006) chama a atenção para a importância da integração dos MCDA aos SIGs, como um subcampo essencial de pesquisa em Ciência da Informação Geográfica. Em áreas urbanas, a importância dessa conjugação diz respeito ao fato de que a urbanização exige mais atenção, onde concentram-se não somente a maior parte considerável da população, mas também a parte principal das forças produtivas transformadoras destes espaços (OVSIANNIKOVA e NIKOLAENKO, 2015).

Segundo Kamp et al. (2003), essas ferramentas são necessárias para avaliar a qualidade atual e futura do ambiente urbano e, eventualmente, possuem a capacidade de avaliar as implicações das políticas de planejamento espacial e urbano em relação a essas dimensões, enquanto produção coletiva. Consequentemente, as abordagens sobre a qualidade ambiental, nos espaços urbanos, se tornam recorrentes na ciência e nas legislações brasileiras. Isso acontece porque, de acordo com Tonetti $(2011$, p. 30), "as áreas urbanizadas concentram a maior parte da população do planeta e representam as maiores alterações provocadas na paisagem pela ação humana".

De acordo com Ariza e Santos (2008, p. 224), é "nas cidades que as pessoas buscam as infraestruturas urbanas e o conforto, entretanto, dentro do caos urbano muitas vezes a qualidade ambiental é perdida". No que diz respeito às legislações municipais de planejamento e gestão urbana, destacam-se a Lei Orgânica Municipal e o Plano Diretor. Ambas incorporam as legislações ambientais, do parcelamento e uso do solo, do zoneamento urbano, do direito à moradia de qualidade e mobilidade urbana. Nesse sentido, a mobilidade "é um componente da qualidade de vida aspirada pelos habitantes de uma cidade. Não há como considerar determinada região habitacional como de alto nível se a mobilidade não estiver presente" (ARAÚJO, 2011, p. 575).

Diante do exposto e em conformidade com Mazetto (2000), a qualidade ambiental não pode ser aferida a partir do levantamento sistemático de uma única variável do ambiente, mas se devem considerar inúmeros fatores na análise e suas múltiplas dimensões. Nesse sentido, e de acordo com Kamp et al. (2003), é necessária a construção de uma estrutura conceitual multidisciplinar de qualidade ambiental e de qualidade de vida para avançar no campo do desenvolvimento urbano, da qualidade ambiental e do bem-estar humano. Além disso, com suporte em diversos autores, Kamp et al. (2003) afirmam que a qualidade ambiental se dá ainda em função das características físicas e sociais, mas também, simbólicas.

Para a Geografia Urbana, a proposta de Nucci (2001) revela que os estudos da qualidade ambiental devem considerar os atributos ambientais, dentre os quais: o uso do solo, poluição, espaços livres e de lazer, verticalidade das edificações, inundação, densidade populacional e cobertura vegetal, espacializados e integrados, em escalas de análise que variem entre 1:2.000 até no máximo 1:10.000. Desta forma, e assentada na espacialização e agrupamento de atributos urbanoambientais, a proposta de Nucci $(2001 ; 2008 ; 2010)$ procura qualificar o ambiente por meio da presença ou ausência de indicadores negativos, ou seja, daqueles desfavoráveis à qualidade ambiental. Para o autor, "a qualidade do ambiente é uma parte fundamental da qualidade de vida humana, que abrange diversos fatores, como os socioeconômicos e os ambientais" (NUCCl, 2008, p. 11).

Ademais, a qualidade ambiental de que se trata este texto se fundamenta nas teorias da Geografia Urbana. Assim, "do ponto de vista da Geografia Urbana podemos pensar o urbano como o modo pelo 
qual a reprodução do espaço se realiza na contemporaneidade, como realidade e como possibilidade" (CARLOS, 2012, p. 95). Nessa perspectiva, destacam-se as análises que revelam como as pessoas se relacionam através de suas atividades e como isso contribui para produção do espaço. Desse modo, nesta pesquisa, os métodos indiretos de análise operacionalizaram as técnicas cartográficas utilizadas e são descritos em detalhes, no Tópico Materiais e Métodos.

Entretanto, em concordância com Minaki e Amorim (2007), salientamos as limitações que a cartografia de síntese pode trazer, em representar paisagens dinâmicas e em processo de evolução. Como solução, os referidos autores chamam a atenção para a adoção de indicadores integrados e sistémicos da paisagem. Neste sentido, Schmidt et al. (2005) apontam as dificuldades de selecionar tais indicadores, que atestam a qualidade ambiental das cidades, apresentando como recomendação o mapeamento de forma distributiva das áreas verdes e de espaços públicos de lazer.

Nesta questão, podemos recorrer novamente à proposta de Nucci (2001), quando expõe a elaboração da Carta de Qualidade Ambiental do Distrito de Santa Cecília/SP, baseada no método de Ecologia e Planejamento da Paisagem. Trata-se de uma técnica fundamentada na abordagem sistêmica, na qual os atributos têm o mesmo peso. Como resultado da sobreposição de sete cartas temáticas que caracterizam o espaço urbano, Nucci (2001) realizou uma avaliação qualitativa deste distrito. Verificou a heterogeneidade na distribuição dos índices de qualidade e de seus valores relativos, que igualmente se pode acatar neste artigo, o fato de que uma determinada área apresentar somente uma ou até mesmo nenhuma variável negativa "não significa na íntegra que a qualidade ambiental seja adequada, porém, pode-se dizer que ela é menos pior que as outras áreas avaliadas" (NUCCl, 2001).

\section{ÁREA DE ESTUDO}

Fundado em 1852, o município de Imperatriz - MA está localizado na Mesorregião Oeste Maranhense (Figura 1). Faz divisa, a oeste, com o estado do Tocantins, separado pelo rio de mesmo nome, possui uma área de $1.368,987 \mathrm{~km}^{2}$, dos quais somente $92,780 \mathrm{~km}^{2}$ são classificados pelo IBGE (2010) como área urbana. Esta pequena área urbana abriga, sozinha, 92\% de sua população, que segundo informações do último censo demográfico de 2010 era de 247.505 habitantes (IBGE, 2010), colocando-se, portanto, como a segunda maior população municipal do Estado.

O município apresenta áreas com predomínio de Formação Florestal Mista, que para Ab'Sáber (2012) são domínios das Terras Baixas Florestadas Equatoriais (Formação Amazônica) e dos Chapadões Tropicais Interiores com Cerrado e Florestas-Galeria (Formação Cerrado). Do ponto de vista do seu povoamento, Imperatriz foi ocupada por diversas frentes de expansão, como denotado em Santos e Nunes (2018). Seu núcleo urbano possui status hegemônico em vários setores, concentrando serviços de saúde, comércio, hotelaria, turismo, educacionais, empresariais e imobiliários (FRANKLIN e SOUSA, 2013). Atualmente, este espaço passa por diferentes processos, sendo um deles o de expansão do tipo verticalizada, como preconiza Oliveira (2017).

Sua geologia é composta por folhelhos laminados, de coloração cinza, com lentes carbonáticas e níveis com estromatólitos, denominados Formação Codó (COSTA NETO, et al., 2014). Na região as litofácies associadas a essa formação, possuem indicativos de deposição em ambiente lagunar com influências marinhas (COSTA NETO, et al., 2014). É marcante ainda a presença de depósitos aluvionares constituídos por sedimentos clásticos arenosos e argilosos, com níveis de cascalho e matéria orgânica, inconsolidados, relacionadas às planícies atuais do rio Tocantins e outros (COSTA NETO, et al., 2014).

De acordo com os padrões de relevo destacados por CPRM (2014) a geomorfologia da área urbana de Imperatriz é composta essencialmente por planícies fluviais nos setores que guardam maior proximidade ao rio Tocantins, por terraços fluviais nos domínios centrais da cidade e nas áreas de urbanização menos intensas, localizadas a nordeste, predominam as superfícies aplainadas degradadas. 
Figura 1 - Localização do município de Imperatriz do Maranhão.

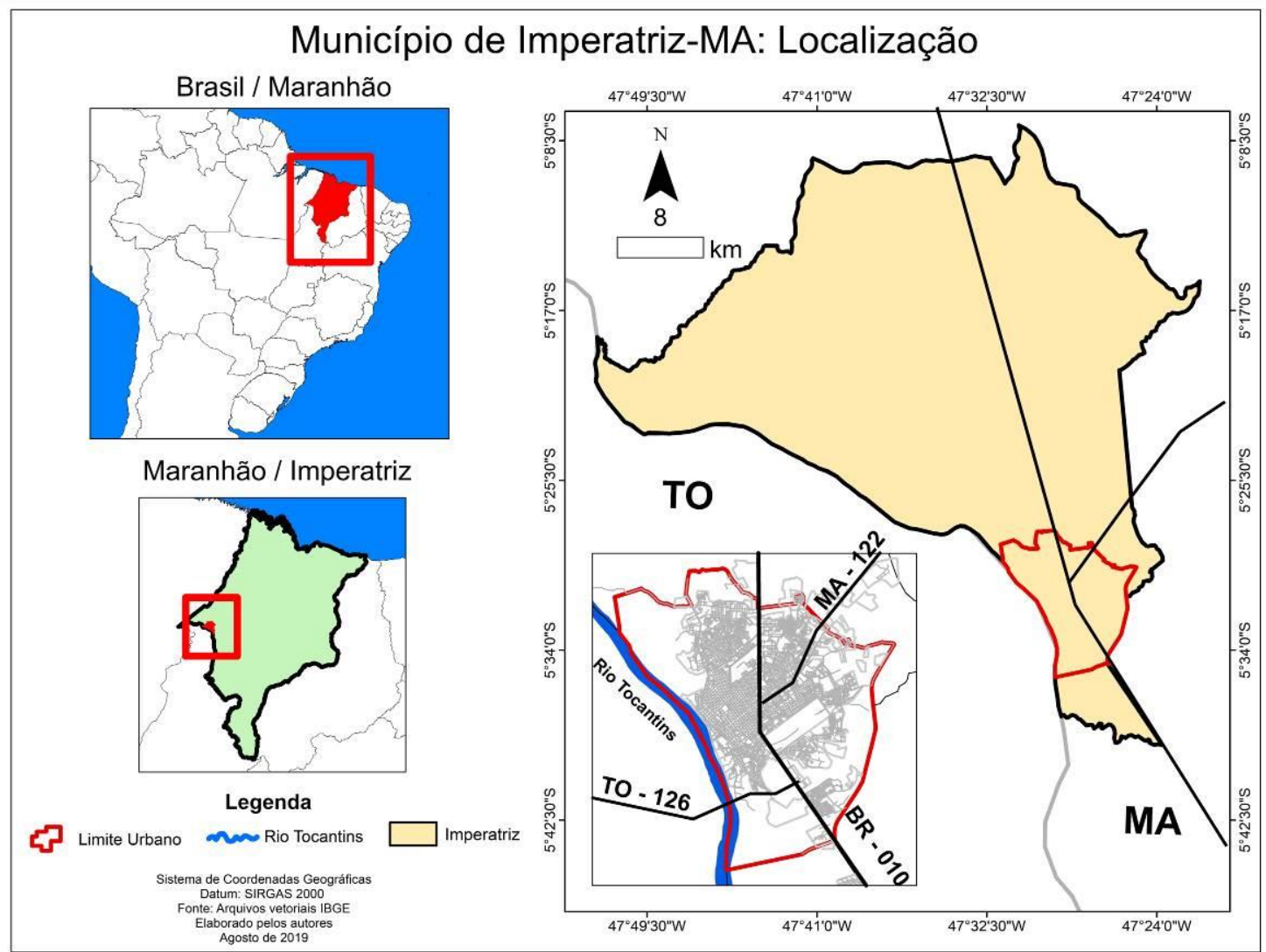

Fonte dos dados - IBGE, IMESC. Concebido pelos autores (2019).

No seguimento das polarizações exercidas pela cidade, Araújo (2017) ressalta a importância desta capital regional no que diz respeito à prestação de assistência à saúde e de polo universitário. Argumento este reforçado por Sousa (2015), quando observa a questão dos serviços, em especial os seguimentos atacadista e varejista, todos responsáveis pela atração de um grande fluxo de pessoas.

Recentemente, grandes empreendimentos comerciais se instalaram na cidade (PANTOJA e PEREIRA, 2019), fato que contribuiu, associado aos empreendimentos imobiliários, para o adensamento de sua malha urbana. Todas essas questões acabam por gerar fatores que desencadeiam problemas na qualidade ambiental da cidade, visto que seus espaços urbanos não planejados se diferenciam segundo a oferta de serviços públicos essenciais, além dos riscos naturais, acentuados pelo processo de ocupação em áreas sujeitas ao regime de cheias do Rio Tocantins.

\section{PROCEDIMENTOS METODOLÓGICOS}

As variáveis da paisagem foram mapeadas usando imagens de alta resolução espacial do Google Earth Pro (2017) e do Google Street View, visualizadas no software QGIS 2.18 e validadas, posteriormente, com inspeções feitas in loco. A análise ocorreu com base na adaptação da metodologia de classificação da paisagem, para áreas urbanas, proposta por Nucci $(1998 ; 2008$; 2010). Essa metodologia pressupõe a classificação do espaço urbano segundo variáveis básicas que interferem na qualidade ambiental.

O método prevê que as variáveis sejam cartografadas em escalas de detalhe e, posteriormente, analisadas por meio de cartas temáticas. Desta forma, a qualidade ambiental foi formulada a partir da junção de indicadores que afetam as particularidades do ambiente urbano, representados pelas variáveis negativas e por alguns critérios que possam melhorar a qualidade de vida do cidadão (Figura 2). 
Figura 2 - Etapas de classificação da paisagem.

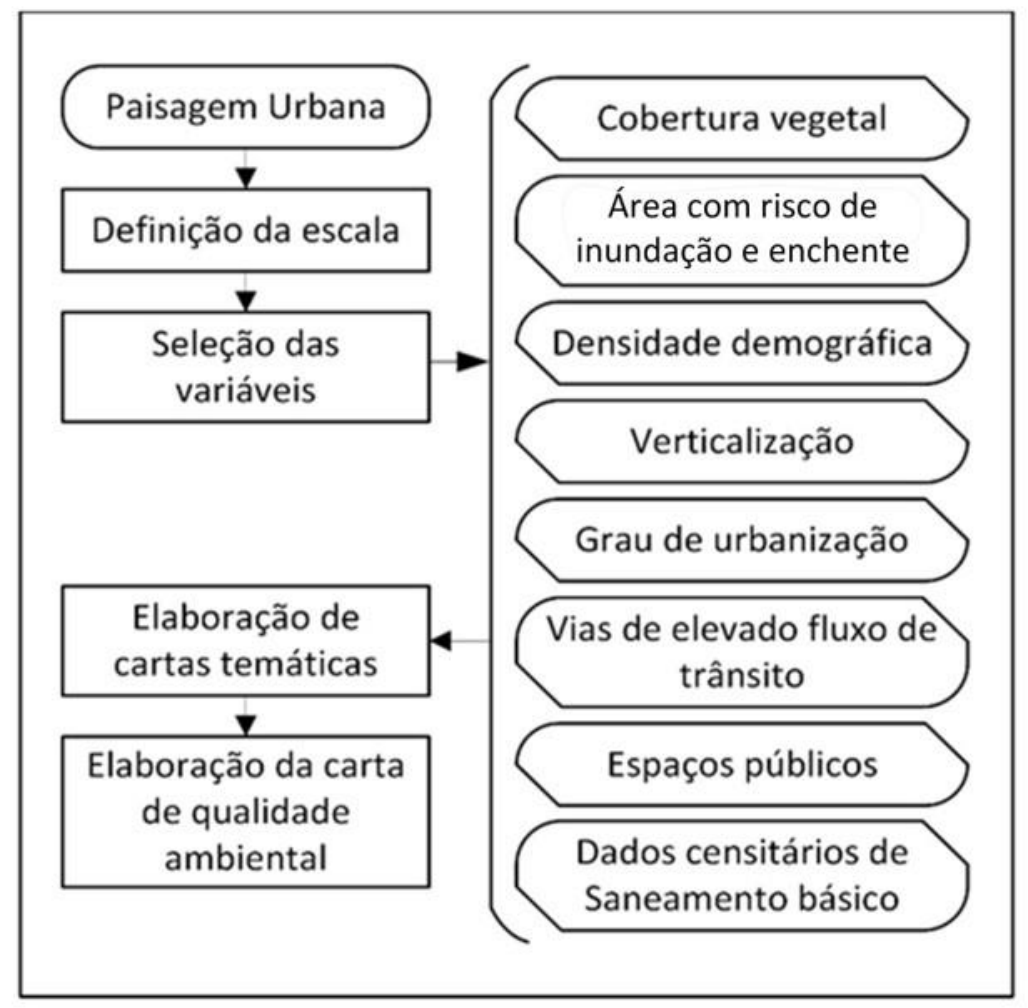

Fonte - Adaptada de NUCCI (1998).

Dentre os indicadores considerados na Figura 2, é importante ressaltar que estes foram enquadrados em dois grupos, observando-se as propostas metodológicas de Nucci (1998) e de Valaski (2013). O primeiro grupo representa os aspectos em que, por si só, a presença na paisagem contribui para o comprometimento da qualidade ambiental, tais como as áreas de risco às inundações e alagamentos, a verticalização das edificações, o grau de urbanização elevado, a elevada densidade demográfica, a falta de saneamento básico e vias com fluxos intensos de trânsito.

Já o segundo grupo engloba elementos como a vegetação e os espaços públicos de lazer, ou seja, elementos que possam contribuir para a melhoria da qualidade ambiental. Assim, a ausência ou escassez destas duas variáveis, em determinadas regiões do perímetro urbano de Imperatriz, foi considerada como um indicativo negativo a qualidade de vida do cidadão.

$\mathrm{Na}$ elaboração das cartas temáticas a vegetação foi vetorizada manualmente, sobre a imagem digital do Google Earth Pro (2017), em uma escala aproximada de 1:5.000. A escala trabalhada permitiu mapeá-la dentro dos lotes urbanos, canteiros de rodovias e nas manchas de remanescentes florestais, ainda presente no município. Para o sítio urbano, no que se refere ao grau de urbanização, a unidade básica de mapeamento adotada foi o quarteirão. Em cada unidade foi calculado o valor da parcela da área construída e, em seguida, divido este valor pelo total da área do quarteirão. Os resultados foram fatiados em três intervalos de valores correspondentes as classes mapeadas.

Desta forma, adotou-se como parâmetros de enquadramento as classes de urbanização "alta", "média" e "baixa", representadas respectivamente, pelas cores, vermelho, laranja e amarelo (Figura 3). Segundo Fantin et al. (2007), as áreas urbanas com alta e média taxa de urbanização podem ser consideradas inadequadas para a implantação de novos progranas habitacionais, "devido a inexistencia de espaços livres, nessas áreas, uma vez que quase todos os terrenos são ocupados por construções". A verticalização, por sua vez, foi levantada visualmente sobre a imagem do Google Earth Pro e foram considerados edificações a partir de três pavimentos. 
Figura 3 - Etapas de elaboração das cartas temáticas do grau de urbanização, densidade demográfica, vegetação e qualidade do saneamento.

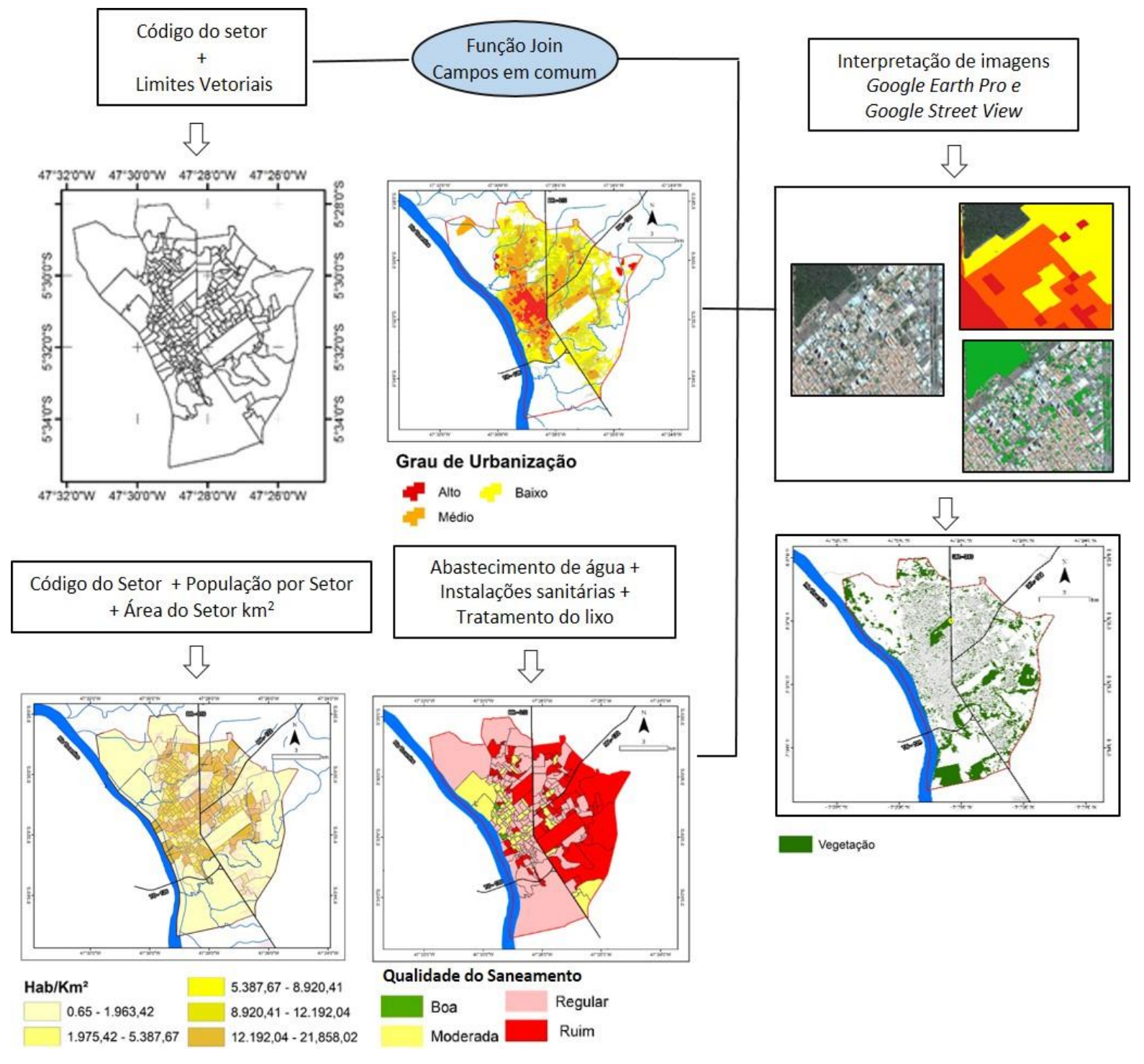

Elaboração - os Autores (2019).

Já a carta da densidade demográfica foi elaborada a partir de dados censitários do IBGE (2010), pelo método coroplético (Figura 3), e as informações das áreas de risco de inundações e alagamentos, compiladas da Carta de Suscetibilidade a Movimentos Gravitacionais de Massa e Inundações (Escala: 1:100.000) e do Mapa de Reconhecimento de Áreas de Alto e Muito Alto Risco a Movimentos de Massa e Alagamentos, ambos provenientes do Serviço Geológico do Brasil (CPRM, 2012). A carta da qualidade do saneamento básico teve por base a proposta metodológica de Genovez (2002). Assim, seguindo a referida proposta, considerou-se como variáveis representadas por setores censitários o número de domicílios com: abastecimento de água tradada; instalação sanitária e coleta de lixo (Figura 3). No caso do abastecimento de água, foram considerados os domicílios conectados a uma rede geral de distribuição de água. Como instalação sanitária, os domicílios com banheiro de uso exclusivo dos moradores e com esgotamento sanitário, via rede geral de esgoto. E, no caso da coleta de lixo, os domicílios com coleta realizada pelo serviço público de limpeza, fornecido pela prefeitura.

As vias de tráfego mapeadas foram as principais rodovias de acesso ao município, que atravessam o mesmo, e as avenidas internas de fluxos intensos entre os bairros. A coleta de informações sobre o sistema viário fundamentou-se, inicialmente, na Lei № 1.069/03, que estabelece as diretrizes para o

$\begin{array}{lllll}\text { Caminhos de Geografia } \quad \text { Uberlândia-MG } & \text { v. 21, n. } 78 & \text { Dez/2020 } & \text { p. 01-20 } & \text { Página } 8\end{array}$


plano diretor urbano (IMPERATRIZ, 2003). Nesta, o Art. 86 determina o nível de hierarquia do sistema viário urbano, segundo o qual 22 ruas ou trechos de ruas de Imperatriz são considerados de hierarquia primária. Além disso, avaliou a distribuição e importância desses trajetos em relação à malha urbana e aos seus pontos interconectados, o que os configurou como verdadeiras espinhas dorsais na cidade. Em seguida, esses trechos foram percorridos a pé, examinando-se a presença, ou não, de fluxos intensos de veículos em relação à trajetos adjacentes. A avaliação in loco aconteceu durante duas incursões de campo, em diferentes horários, as quais serviram de base para confirmação do mapeamento.

Para a execução deste trabalho, definiu-se que as vias com tráfego intenso possuem um distanciamento de influência de 50 metros, onde os seus efeitos negativos são percebidos com maior intensidade pela população. No caso de Imperatriz, este buffer equivale aproximadamente à metade do quarteirão, para além das duas margens das rodovias ou avenidas (Figura 4). Assim, o valor do distanciamento foi definido empiricamente e de acordo com a realidade da cidade, que apresenta pequenos quarteirões, em sua maioria, disformes e mal planejamentos.

Figura 4 - Etapas de elaboração das cartas temáticas: buffer das vias com elevada intensidade de fluxos e dos espaços públicos.

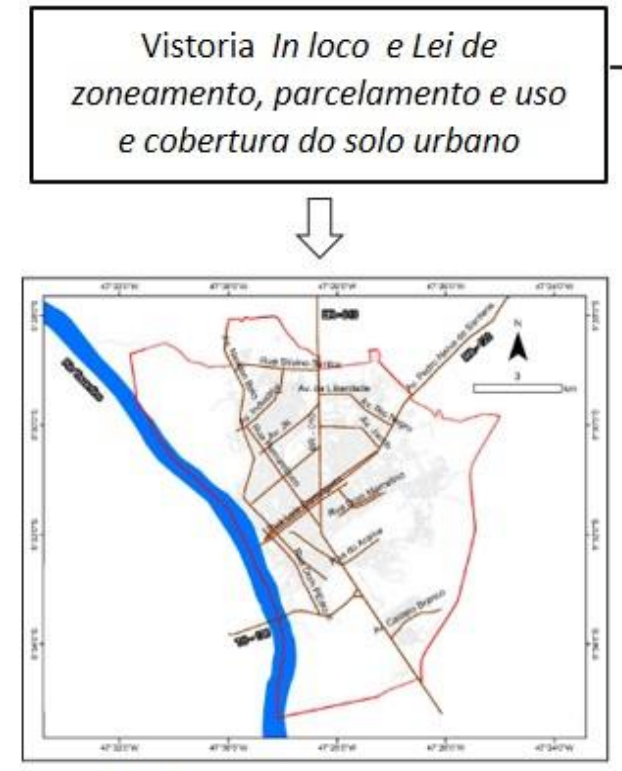

Vias

$\checkmark$ Fluxo elevado de trânsito

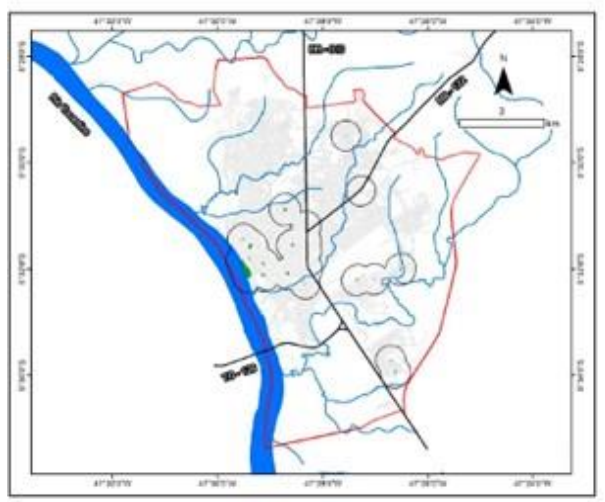

Espaços Públicos

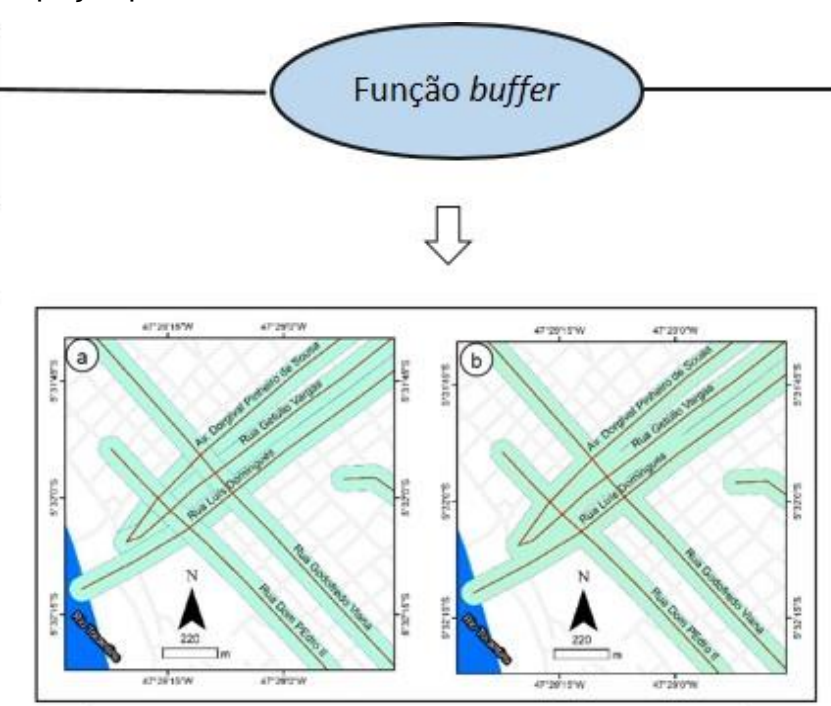

(a) criação dos buffers com 50 m; (b) buffers dissolvidos.

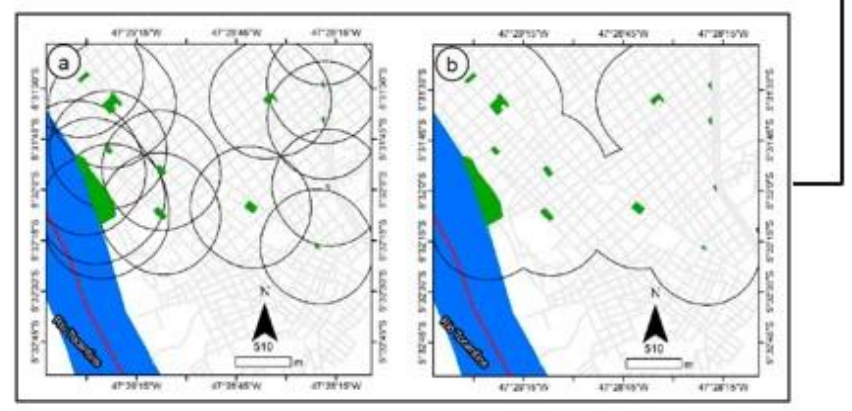

(a) criação dos buffers com 500 m; (b) buffers dissolvidos.

Elaboração - os Autores (2019). 
Com relação aos espaços públicos abertos de convivência, foram identificados os elementos pertencentes à categoria praças. Essas apresentam ao menos duas tipologias definidas, em relação ao tamanho e à quantidade de infraestruturas. Como as praças exercem uma função cênicapaisagística e de convivência à população local, delimitou-se um raio de influência de 500 metros, ponderado como a distância de referência a ser percorrida a pé (Figura 4). Para tanto, foi levada em consideração a caminhabilidade de deslocamento médio da população, avaliada por Mcgarigal et al. (1995) em diversas cidades dos Estados Unidos, a qual, neste trabalho, foi adaptada para a realidade de Imperatriz.

Por fim, a confecção da carta de qualidade ambiental urbana foi realizada por meio da análise multicritério, via combinação por somatória das variáveis, para a geração do arquivo raster final. Nesse processo, todas as variáveis receberam o mesmo valor "peso" de importância, que foi igual a 1. Assim, o mapa de qualidade ambiental gerou como resultado um raster composto, que varia o grau de qualidade ambiental entre o valor do quantitativo de variáveis consideradas, que no caso deste trabalho foram 9. Nesse sentido, as áreas com valores próximos de 0 são aquelas com melhor qualidade ambiental, e aquelas onde os valores se aproximam do número máximo de variáreis negativas são áreas com qualidade ambiental insatisfatória, portanto, com maior quantidade de atributos que indicam grau de comprometimento da qualidade da paisagem.

Para o mapa final da qualidade ambiental urbana de Imperatriz, adotou-se neste artigo a escala classificatória apresentada por Fantin et al. (2007), que integra o Índice de Qualidade Ambiental de Genovez (2002). A escala de classificação é constituída por um padrão de referência de escalonamento qualitativo (bom, moderado e ruim), que permite identificar as áreas mais precárias e menos precárias em relação a uma conjugação de variáveis que mensuram a qualidade ambiental. Assim, os referidos autores (2007) consideraram aspectos como a ausência ou a presença de infraestrutura urbana e a localização periférica, ou não, para a análise da qualidade ambiental e da implantação de novos assentamentos humanos, na zona leste do município de São José dos Campos - SP.

Ademais, destaca-se o fato de que alguns mapas provenientes de outras pesquisas não possuem todos a mesma escala cartográfica. Essas diferenças puderam ser amenizadas durante a etapa de conversão de arquivos vetoriais em raster, atribuindo o mesmo tamanho de pixels a todas as bases cartográficas. Essa fase do processamento de dados e a integração da base cartográfica foi realizada no software ArcGis, versão para estudante. Desta forma, os mapas temáticos das 9 variáveis consideradas puderam ser interpolados via álgebra de mapa, gerando o produto final.

Segundo Santos e Ventorini (2017, p. 5), "as análises por meio de álgebras de mapa permitem modelar um sistema a partir de critérios considerados importantes", cujo resultado é a modelagem da realidade de um determinado sistema, em ambiente computacional. Como suporte técnicometodológico, tem-se a análise multicritério, formulada por um conjunto de técnicas para auxiliar a tomada de decisão. No Brasil, já existem algumas pesquisas que têm revelado o potencial deste conjunto de técnicas, para mapeamento da qualidade ambiental em regiões urbanas (SANTOS et al., 2012; BARBOZA, 2014; TONETTI et al., 2018).

\section{RESULTADOS E DISCUSSÕES}

\section{OS INDICADORES DA PAISAGEM DO ESPAÇO URBANO DE IMPERATRIZ-MA}

Como primeiro resultado deste trabalho foram confeccionadas cartas temáticas que refletem as características dos elementos da paisagem urbana de Imperatriz, buscando um diagnóstico mais apurado dos fatores que comprometem a qualidade ambiental deste município. Deve-se levar em consideração que, embora haja transição entre o grau de comprometimento que as 9 variáveis, mostradas abaixo, oferecem à paisagem, para efeito desta análise, foram acatados somente aqueles que se configuram como indicadores negativos, ou a sua ausência e escassez na paisagem contribuem para a diminuição do bem-estar social (Figura 5). 
Figura 5 - Indicadores utilizados na composição da qualidade ambiental urbana.

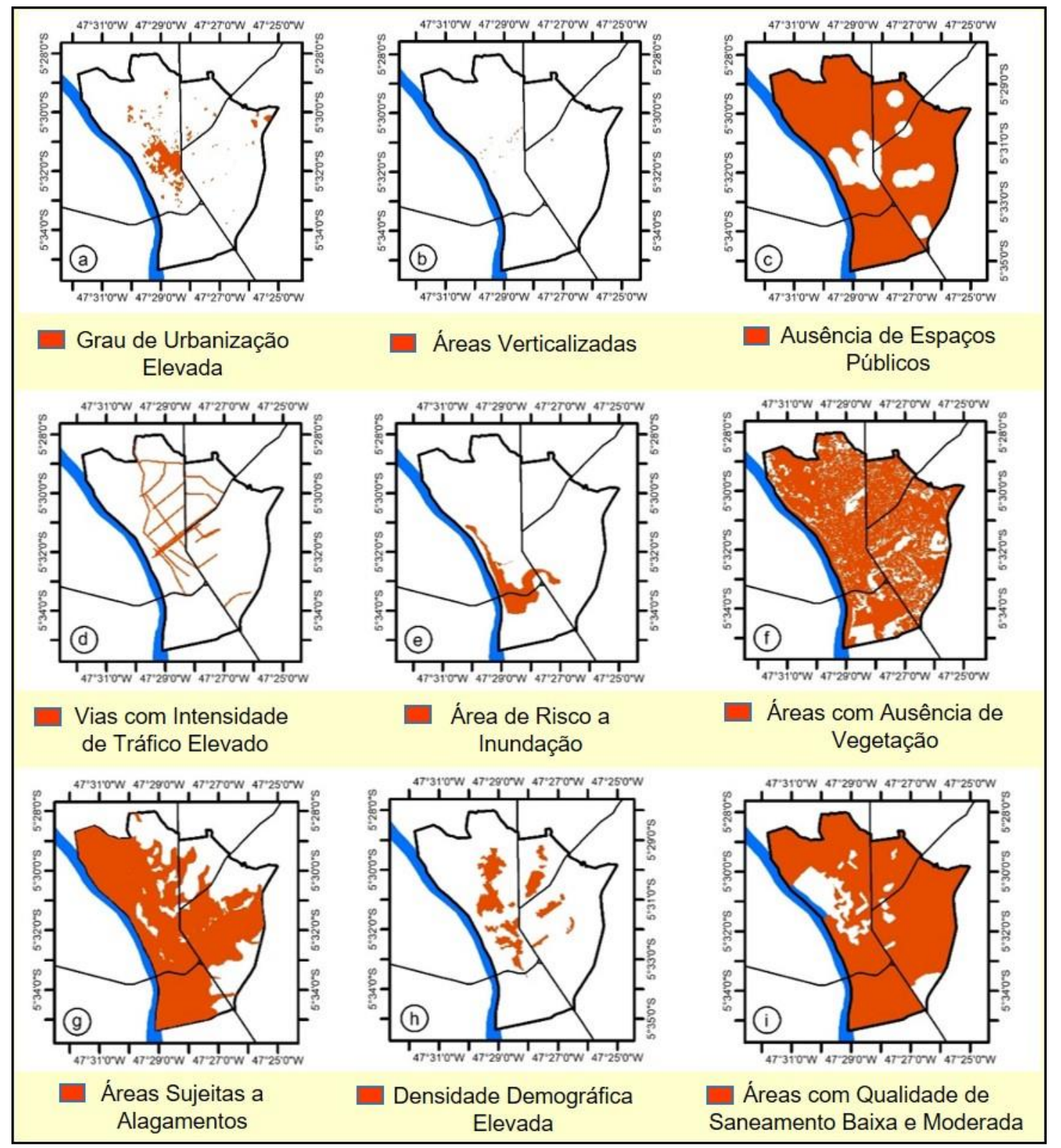

Elaboração - os Autores (2019).

No que diz respeito ao grau de urbanização de Imperatriz, este foi classificado em alto, médio e baixo, levando-se em consideração o teor das áreas edificadas, entendido neste trabalho como a densidade de residências por unidade de área representada pelo quarteirão. Dessa forma, obteve-se um cenário do espaço urbano no qual ficaram evidenciadas quais são as áreas de concentração das estruturas urbanas. Como efeito, o grau de urbanização alto (Figura 5a) está presente na porção central da cidade, demonstrando manter ligações mais expressivas com as principais vias de acesso, a exemplo da rodovia BR-010 e da avenida Pedro Neiva de Santana.

Da quantificação destes dados, o percentual do grau de urbanização alto em relação ao total do perímetro urbano atingiu cerca de $10 \%$, representando pouco menos de $5 \mathrm{~km}^{2}$ de área. Por sua vez, o grau de urbanização classificado como médio representa $13,20 \mathrm{~km}^{2}$ da área da cidade, ou seja, cerca de $27 \%$ desta. Esses resultados são importantes, pois na perspectiva de Ovsiannikova e Nikolaenko (2015), a constatação do grau de urbanização elevada permite posicionar as regiões em termos de implicações da qualidade do ambiente, fazer comparações inter-regionais e corrigir atividades de expansão urbanas e orçamentárias de fomentos às habitações. 
Já o grau de urbanização baixo foi equivalente a $30,63 \mathrm{~km}^{2}$. Com isso, teve-se um número percentual da ordem de $63 \%$ referente a essa classe. Essas áreas estão distribuídas espacialmente em setores mais afastados do centro da cidade e em grande parte ao lado direito da rodovia BR-010.

A verticalização de Imperatriz-MA, exposta na figura $5 b$, ainda é muito incipiente, se comparada com cidades situadas em outros estados brasileiros. Apesar da incipiência, a verticalização é um aspecto que emana forte concentração em Imperatriz. Em primeiro plano, a maioria quase absoluta dos edifícios está situada entre o Rio Tocantins e a rodovia BR-010. Em segundo, essa concentração se deu nos bairros Três Poderes e Maranhão Novo. Tradicionalmente, estes são bairros habitados por pessoas com alto padrão de renda social.

Com relação aos espaços públicos abertos de convivência, verificou-se que a sua presença está ligada ao centro da cidade, sendo representados na totalidade por praças (Figura 5c). Ao todo, foram identificadas 23 praças, apresentando ao menos duas tipologias definidas em relação ao tamanho e quantidade de infraestruturas. As maiores são as praças Beira-Rio, da Bíblia, Mané Garrincha, Brasil e de Fátima. Sendo aquelas que dispõem de melhor infraestrutura, as praças Beira-Rio e Mary de Pinho. A primeira requalificada recentemente e a segunda construída a partir do ano de 2014. Com relação à infraestrutura, em sua maioria as praças estão em condições de degradação, com infraestruturas comprometidas ou inexistentes, abandonadas pelo poder público administrativo.

$\mathrm{Na}$ identificação das áreas de risco, representadas pelas figuras $5 \mathrm{e} \mathrm{e} 5 \mathrm{~g}$, foram utilizados dois fatores, as inundações e os alagamentos. Essas áreas apresentam historicamente problemas decorrentes das cheias do Rio Tocantins. Conforme o Serviço Geológico do Brasil - CPRM (2012), são 1 mil imóveis e cerca de 4 mil pessoas em situação de risco. A solução apresentada pelos técnicos do CPRM é a remoção das moradias e famílias, bem como a limpeza e dragagem do rio de acordo com o período de maior vazão, visto que esse rio recebe dejetos, esgotos e entulhos ao longo de seu curso.

A vegetação mapeada corresponde a algumas manchas de vegetação nativa, ainda presentes e de vegetação reflorestada. Essas, na maioria das vezes, encontram-se espalhadas pelas rodovias e avenidas e dentro das quadras urbanas. Tais coberturas vegetais apresentam extratos variados, podendo ir de alto até baixo, e segundo Nucci e Cavalheiro (1999), podem ser classificadas como contínuas ou dispersas. Geralmente, a vegetação dispersa, caso de parcela considerável do perímetro urbano de Imperatriz, é típica de área urbana edificada, com exceção das praças e das regiões mais periféricas, onde se verifica ainda algumas espécies arbóreas preservadas (Figura $5 f$ ). Em termos de representatividade, a vegetação total mapeada em 2017 ocupa uma área de 38,09 $\mathrm{km}^{2}$, ou seja, $41,05 \%$, enquanto a vegetação que corresponde à porção edificada da área urbana é de apenas $7,82 \mathrm{~km}^{2}$, equivalente a $8,43 \%$. A importância da análise do verde urbano diz respeito ao fato de que, segundo o Ministério do Meio Ambiente (MMA, 2016), as áreas verdes contribuam de modo significativo para a qualidade de vida e o equilíbrio ambiental no meio urbano.

A figura 5 h retrata os setores com maior densidade populacional urbana. É possível perceber uma alta concentração na parte antiga da cidade, que configura o seu núcleo central, bem como ao longo de trechos da BR-010 e da avenida Pedro Neiva de Santana, onde também se localizaram os maiores índices de urbanização. Nesse sentido, o limiar de $8.920,41$ hab. $/ \mathrm{km}^{2}$ foi definido por ser o fator restritivo para uma boa qualidade do adensamento populacional, alicerçado no valor intermediário alto em relação a todos os níveis de densidade dos setores censitários mapeados. Este fenômeno é recorrente em cidades brasileiras, pois segundo Tucci (2008), desde o século passado, o desenvolvimento urbano passou a criar padrões de concentração urbana, decorrentes da convergência do setor de prestação de serviços e das indústrias.

Quanto à qualidade dos serviços básicos de saneamento, istó está subordinado à universalização deste benefício prestado pela Prefeitura Municipal de Imperatriz e pela Companhia de Saneamento Ambiental do Maranhão (CAEMA), que ainda é uma meta distante de ser alcançada. Assim, a predominância das classes regular e ruim se intensifica, cobrindo não somente as áreas periféricas de seu perímetro urbano, mas também diversos bairros centrais da cidade (Figura 5i). Tal fator remete a uma parcela de cerca de $87 \%$ da área com situação precária no que diz respeito à questão 
de abastecimento de água tradada, instalação sanitária e coleta de lixo. Neste contexto, Tucci (2008) menciona que a ausência ou ineficiência na coleta, tratamento e destinação correta de esgoto sanitário impacta o ambiente urbano e influencia sobre a saúde da população. O Plano Nacional de Saneamento Básico (2013) recomenda, quando há ausência da rede de coleta de esgoto, o uso de fossas sépticas, contudo, em áreas sujeitas a inundações esse sistema não é eficaz, pois nos períodos de inundação a água se junta ao esgoto, se espalhando por vastas regiões.

\section{MAPA SÍNTESE DE QUALIDADE AMBIENTAL URBANA}

A carta síntese de qualidade ambiental (Figura 6) mostra-se, em geral, com valores bem distribuídos em relação àqueles que se encontram na gradação de "moderada" qualidade. Porém, é perceptível que as áreas com pior qualidade ambiental se concentram em setores centrais da cidade, geralmente localizados entre o Rio Tocantins e a rodovia BR - 010. Estes locais são marcados por uma configuração de fatores negativos que revelam o alto grau de urbanização, elevada densidade demográfica, vias e avenidas com tráfegos intensos, além de serem áreas sujeitas aos alagamentos e inundações das cheias do Rio Tocantins, com qualidade de saneamento básico regular a ruim. Algumas exceções podem ser encontradas em bairros centrais, que são melhor beneficiados com áreas verdes e espaços públicos de lazer, e com qualidade de saneamento mais "moderada".

Figura 6 - Carta síntese da qualidade ambiental urbana de Imperatriz - MA (ano 2017).

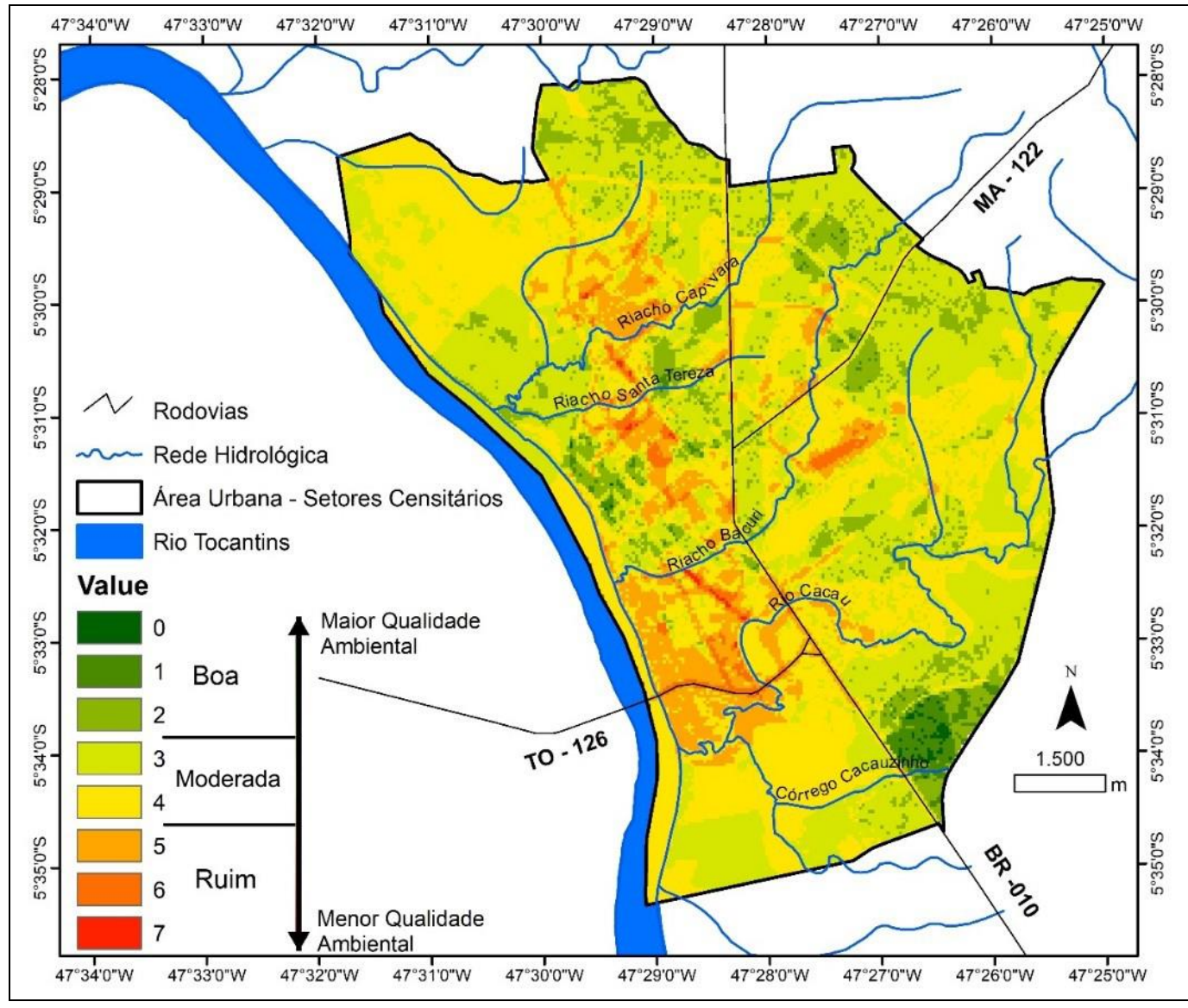

Elaboração - os Autores (2019).

A qualidade ambiental, classificada como "boa", está mais concentrada nas porções periféricas do perímetro urbano de Imperatriz, onde a presença dos atributos negativos da paisagem é menor. Apesar de possuírem uma qualidade de saneamento básico regular a ruim, estas áreas estão livres do tráfego intenso, da alta densidade demográfica, dos aglomerados urbanos e das intempéries das

$\begin{array}{lllll}\text { Caminhos de Geografia } \quad \text { Uberlândia-MG } & \text { v. 21, n. 78 } & \text { Dez/2020 } & \text { p. 01-20 } & \text { Página } 13\end{array}$ 
cheias do Rio Tocantins. Um fator a ressaltar é que a área com a melhor qualidade ambiental constatada, com valores entre 1 a 0 de variáveis negativas, ocorreu devido a uma melhora na questão da qualidade do saneamento básico, de uma pequena localidade à sudeste da região mapeada. Fantin et al. (2007), em seu estudo da qualidade ambiental urbana em São José dos Campos, também verificaram uma melhora da qualidade onde existe boa infraestrutura básica e um adensamento urbano que ainda não saturou o sistema viário local.

Análise similar foi realizada por Loghin e Murtoreanu (2017), na cidade de Bucareste, capital da Romênia. Para os referidos autores, os resultados desses tipos de estudos são úteis para subsidiar projetos de remodelação urbana, o que significa encontrar os locais mais adequados para a construção de novos bairros de caráter residencial e realizar melhorias da mobilidade entre eles, favorecendo redes de circulação urbana, infraestrutura básica e espaços de entretenimento. Segundo Boareto (2003, p. 49), "a mobilidade urbana é função pública destinada a garantir a acessibilidade para todos e esse objetivo implica na obediência de normas que atendam às diferentes demandas de deslocamentos".

No que se refere à quantificação e concentrações das variáveis analisadas, os dados do Quadro 1 chamam a atenção para o fato de que $78,37 \%$ do perímetro urbano apresentaram 3 ou 4 atributos negativos mapeados, o que indica uma qualidade ambiental intermediária. Já as áreas classificadas com a presença de nenhuma (zero), 1 ou 2 variáveis negativas, que são as localidades consideradas como as de melhor qualidade ambiental, são representadas por apenas 10,35\% do perímetro urbano, localizadas em sua periferia ou em regiões centrais muito próximas às áreas de praças onde o verde urbano se faz presente, conjuntamente a um moderado sistema de saneamento básico.

Quadro 1 - Quantidade de variáveis negativas e percentual de concentração no perímetro urbano.

\begin{tabular}{|c|c|c|c|c|}
\hline Qualificativo & Valor de Q. Ambiental & $\begin{array}{c}\text { Área da Classe } \\
\text { km }^{2}\end{array}$ & Área do Qualificativo $\mathrm{km}^{2}$ & Área \% \\
\hline \multirow{3}{*}{ Boa } & 0 & 0,17 & \multirow{3}{*}{9,57} & \multirow{3}{*}{10,35} \\
\hline & 1 & 1,39 & & \\
\hline & 2 & 8,00 & & \\
\hline \multirow{2}{*}{ Moderada } & 3 & 36,45 & \multirow[b]{2}{*}{72,4} & \multirow[b]{2}{*}{78,37} \\
\hline & 4 & 35,95 & & \\
\hline \multirow{3}{*}{ Ruim } & 5 & 8,88 & \multirow{3}{*}{10,4} & \multirow{3}{*}{11,28} \\
\hline & 6 & 1,43 & & \\
\hline & 7 & 0,09 & & \\
\hline
\end{tabular}

Fonte - Autores (2019).

A presença de 5,6 ou 7 variáveis negativas, que indicaram os espaços com a pior qualidade ambiental, enquadrados como "ruim", são representadas por $11,28 \%$ do total mapeado. Rotineiramente, são áreas com proximidades ao centro da cidade, ou seja, bairros com desenvolvimento urbano mais antigo. É importante ressaltar que, das regiões mapeadas dentro do perímetro urbano de Imperatriz, nenhuma apresentou uma somatória dos 9 indicadores negativos considerados.

Para verificar a influência do processo de expansão da cidade na qualidade ambiental, a Figura 7 apresenta a relação entre as classes mapeadas com o processo de evolução por décadas da malha urbana, a partir do surgimento de seus bairros, dos mais antigos aos mais recentes. Entretanto, ressaltamos a malha urbana atual, formada por arruamentos e loteamentos, que constituem os limites dos bairros de Imperatriz (WikiMapia e IBGE, 2010). 
Figura 7 - Qualidade ambiental estratificada e classificação por década de origem dos bairros.

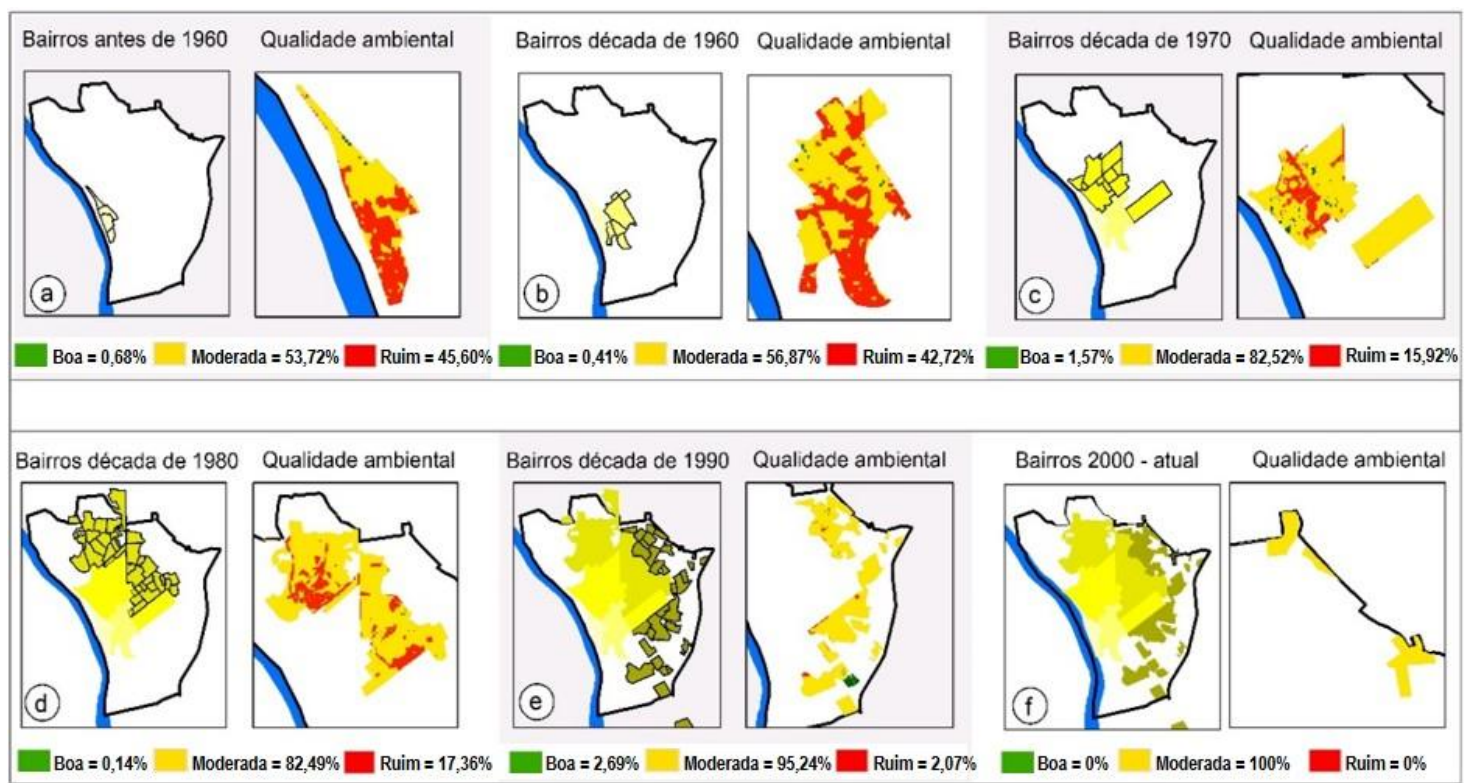

Elaboração - os Autores (2019).

Dos dados analisados da Figura 7, é evidente que a qualidade ambiental mantém uma relação direta com a incorporação de novas áreas ao perímetro urbano, em outras palavras, com o crescimento da cidade. Essa relação corrobora afirmar que a qualidade ambiental "moderada" intensificou-se, conforme o recorte temporal das unidades setoriais de bairros que tiveram um desenvolvimento maior, passando de $53,72 \%$ da malha urbana existente antes de 1960 (Figura 7a) para $100 \%$ das áreas que representam os bairros criados a partir de 2000 (Figura 7f), que é a conjuntura mais recente mapeada.

Este crescimento foi linear até 1960, quando o valor era de $56,87 \%$ (Figura $7 b$ ), tendo um aumento expressivo a partir da década de 1970 para 82,52\% (Figura 7c). São bairros localizados próximos ao centro da cidade ou até mesmo o delineamento do próprio núcleo central, que foi alterado ao longo deste período. São cortados pela avenida Pedro Neiva de Santana, nome dado à rodovia MA-122 no perímetro urbano de Imperatriz, juntamente com a rodovia BR-010 e a TO-126, que são as principais vias de entrada e saída da cidade, as quais concentram o tráfego intenso e os principais comércios de prestação de serviços.

Já a qualidade ambiental "ruim" revelou um decréscimo positivo em números percentuais, se comparados aos recortes temporais de bairros incorporados mais recentemente à malha urbana, passando de 45,60\% antes de 1960 (Figura 7a) para 0\% em 2000 (Figura 7f). Porém, os percentuais de $45,60 \%$ e $42,72 \%$, considerados ainda elevados, são valores registrados para os bairros criados antes e durante a década de 1960 (Figuras $7 \mathrm{a}$ e $7 \mathrm{~b}$ ), períodos que representam os bairros mais consolidados e antigos de Imperatriz, como o Beira Rio, União, Vila Leandra, Caema, Bacuri, Mercadinho, São José do Egito e Parque Anhanguera.

A situação destes bairros é explicada pelo adensamento da malha urbana e a falta de planejamento da cidade, com a diminuição das áreas verdes e a carência de espaços públicos de lazer, evidenciando bairros com densidade demográfica elevada, com moradias sobre a influência da planície aluvial do Rio Tocantins e subordinadas ainda a melhorias de saneamento básico. Quanto ao percentual da qualidade ambiental "boa", este foi baixo em todos os recortes temporais considerados, apresentado o seu melhor desempenho na década de 1990, com 2,69\% (Figura 7e), período em que se observa a maior incorporação de novos bairros às regiões periféricas da malha urbana de Imperatriz.

Estudo semelhante foi realizado nas cidades de Lodi e Gênova na Itália, avaliando a qualidade urbana de bairros de densidade média. Assim, Delsante (2016), analisando diferentes variáveis condizentes aos serviços básico, espaços públicos e infraestrutura urbana, identificou relações positivas entre qualidade urbana e saúde da população, nestas duas cidades europeias. Igualmente,

$\begin{array}{lllll}\text { Caminhos de Geografia } \quad \text { Uberlândia-MG } & \text { v. 21, n. } 78 \quad \text { Dez/2020 } & \text { p. 01-20 } & \text { Página } 15\end{array}$ 
Tonetti et al., (2018) estudando a qualidade ambiental dos bairros do município de Paranaguá - PR, Brasil, evidenciaram uma melhor qualidade ambiental nas regiões periféricas deste município, em bairros com predomínio de uso residencial e com vias sem tráfego intenso, exceto próximo ao Porto de Paranaguá.

Por fim, foi verificado que os resultados corroboram para a assertiva de Nucci (2001), quando o autor indica as limitações da heterogeneidade da distribuição dos índices de qualidade e de seus valores relativos que as Cartas de Qualidade Ambiental podem apresentar. Da metodologia aplicada e de sua comparação com outros estudos, observou que a carta síntese gerada não pode ser considerada como verdade absoluta, pois esta revelou estar diretamente subordinada à escolha e à quantidade das variáveis ambientais consideradas. Porém, a mesma serve como um bom indicador da configuração urbana dos locais onde se concentram a maior carência de aparatos urbanos.

\section{CONSIDERAÇÕES FINAIS}

Do mapa síntese das variáveis analisadas, permite-se concluir que a qualidade ambiental intermediária é a que prevalece em todo o perímetro urbano de Imperatriz. Dada a diversidade dos indicadores considerados e do próprio cenário da planície de inundação do Rio Tocantins, associada à falta de planejamento urbano da cidade frente ao processo de adensamento de sua malha urbana, poucas foram as áreas que reuniram condições favoráveis a serem atribuídas como de qualidade ambiental "boa". Do mesmo modo, a dificuldade da mobilidade urbana, representada nos setores centrais pelo fluxo de trafego intenso juntamente com a alta densidade da população, favorece a perda da qualidade ambiental, nesta parte mais consolidada da cidade.

Desta forma, fica bem evidente que a qualidade ambiental de uma determinada localidade de Imperatriz mantém uma relação direta com o período ao qual foi anexada ao perímetro urbano da cidade. Neste caso, o período de incorporação de determinada área à malha urbana, representado neste artigo pelo recorte de criação dos bairros, é importante porque denota as infraestruturas existentes, tais como praças, saneamento básico e vias de fluxo asfaltadas. Porém, apresenta alto grau de urbanização e densidade demográfica elevada, o que não ocorre nos bairros de ocupação mais recente. Essa relação corrobora para confirmar que quanto mais próximo do centro urbano, a qualidade ambiental é mais precária, devido à maior somatória de variáreis negativas encontradas nesta região de bairros mais antigos.

É importante destacar que a análise multicritério realizada em ambiente SIG, com a integração de elementos da paisagem, mostrou ser uma ferramenta promissora para a gestão urbana. Esta serve de apoio aos tomadores de decisão, na indicação das regiões que mais necessitam de intervenções administrativas, ou seja, aquelas que apresentaram qualidade ambiental intermediária e ruim. Entretanto, cabe salientar que o produto final é uma carta síntese fruto da ponderação do quantitativo e dos tipos de indicadores selecionados. Assim, recomenda-se que para um diagnóstico mais apurado, que sejam somados outros fatores que mensurem a qualidade ambiental do ar, ruídos sonoros, ilhas de calor, entre outros.

Das discussões teóricas, é importante reforçar que a qualidade ambiental é parâmetro para a qualidade de vida urbana, não podendo ser compreendidas como sinônimos, mas sim como um complemento essencial que caracteriza a qualidade de vida.

\section{AGRADECIMENTOS}

O primeiro autor agradece à Coordenação de Aperfeiçoamento de Pessoal de Nível Superior CAPES, pela bolsa de mestrado concedida.

\section{REFERÊNCIAS}

AB'SÁBER, A. N. Domínios de natureza no Brasil: potencialidades paisagísticas. 7. ed. São Paulo: Ateliê, Brasil, 2012.

ARAÚJO, M. R. M. et al. Transporte público coletivo: discutindo acessibilidade, mobilidade e qualidade de vida. Psicologia \& Sociedade, n. 3, v. 23, 2011. https://doi.org/10.1590/S0102$\underline{71822011000300015}$

$\begin{array}{lllll}\text { Caminhos de Geografia } \quad \text { Uberlândia-MG } & \text { v. 21, n. 78 } & \text { Dez/2020 } & \text { p. 01-20 } & \text { Página } 16\end{array}$


ARAÚJO, J. A. V. de. A Região de Influência de Imperatriz - MA: Estudo da polarização de uma capital regional, destacando a regionalização dos serviços públicos de saúde. Dissertação (Mestrado em Geografia) - Universidade Federal de Pernambuco, Recife - PE, 2017.

ARIZA, C. G.; SANTOS, D. G. Qualidade ambiental e planejamento urbano. Caminhos de Geografia, v.9, n. 26, p. 224-242, 2008.

BARBOZA, J. Z. L. Qualidade ambiental urbana do distrito do Brás, município de São Paulo (SP). Dissertação (Mestrado em Geografia) - Faculdade de Filosofia, Letras e Ciências Humanas da Universidade de São Paulo, São Paulo, 2014.

BERTALANFFY, L. V. S. The History and Status of General Systems Theory. The Academy of Management Journal, v. 15, n. 4, p. 407-426, 1972. https://doi.org/10.5465/255139

BEZERRA, A. F. Qualidade Ambiental Urbana do Distrito Baeta Neves, Município de São Bernardo do Campo (SP). Dissertação (Mestrado em Geografia) - Faculdade de Filosofia, Letras e Ciências Humanas da Universidade de São Paulo, São Paulo, 2008.

BOARETO, R. A mobilidade urbana sustentável. Revista dos Transportes Públicos - ANTP, Ano 23, p. 45-56, 2003.

BUCCHERI FILHO, A. T.; TONETTI, E. L. Qualidade Ambiental nas paisagens urbanizadas. Revista Geografar, Curitiba, v.6, n.1, p. 23-54, 2011. https://doi.org/10.5380/geografar.v6i1.21802

CARLOS, A. F. A. A cidade. 8. ed. São Paulo: Contexto, 2008.

CARLOS, A. F. A. A "Geografia Urbana" como disciplina: uma abordagem possível. Revista do Departamento de Geografia - USP, Volume Especial 30 Anos, p. 92-111, 2012. https://doi.org/10.7154/RDG.2012.0112.0006

CARVER, S. J. Integrating multi-criteria evaluation with geographical information systems. International Journal of Geographical Information Systems, v. 5, n. 3, p. 321-339, 1991. https://doi.org/10.1080/02693799108927858

CINELLI, M.; COLES, S. R.; KIRWAN, K. Analysis of the potentials of multi criteria decision analysis methods to conduct sustainability assessment. Ecological Indicators, v.46, p.138-148, 2014. https://doi.org/10.1016/j.ecolind.2014.06.011

COSTA NETO, M. C. da; LOPES, G. C. dos A.; MELO, A. F. F. de. Geologia da folha Imperatriz SB.23-V-C-V, Estado do Maranhão. Belém: CPRM, Serviço Geológico do Brasil, 2014. 87 p.

CPRM - Companhia de Pesquisa e Recursos Minerais. Carta de suscetibilidade a movimentos gravitacionais de massa e inundação. CPRM, 2014. Escala 1:100.000

CPRM - Companhia de Pesquisa e Recursos Minerais. Ação para reconhecimento de áreas de alto e muito alto risco a movimentos de massas e enchentes. Imperatriz - MA: CPRM, 2012, escala $1: 30000$.

DELSANTE, I. Urban environment quality assessment using a methodology and set of indicators for medium-density neighbourhoods: a comparative case study of Lodi and Genoa. Ambiente Construído, Porto Alegre, v. 16, n. 3, p.7-22, 2016 . https://doi.org/10.1590/s1678$\underline{86212016000300089}$

FANTIN, M.; COSTA, A. A.; MONTEIRO, A. M. V. A relevância de uma infra-estrutura geoinformacional como subsídio ao desenvolvimento de políticas urbanas. In: ALMEIDA, C. M. de; CÂMARA, G.; MONTEIRO, A. M. V. (orgs.). Geoinformação em urbanismo: cidade real x cidade virtual. São Paulo: Oficina de Textos, 2007. p. 132-161

FRANKLIN, A.; SOUSA, J. M. de. Formação socioespacial sulmaranhense: da emergência de Pastos Bons à constituição de uma região policêntrica. In: SOUSA, J. M. de (org.). O regional e o urbano no sul do Maranhão: delimitações conceituais e realidades empíricas. Imperatriz, MA: Ética, 2013. p. 21- 
82.

FERREIRA, M. B. P. Cobertura da terra como indicador de qualidade ambiental urbana: Estudo aplicado ao município de Curitiba-PR. Dissertação (Mestrado em Geografia) - Setor de Ciências da Terra, Universidade Federal do Paraná, Programa de Pós-Graduação em Geografia, Curitiba, 2015.

GASPARATOS, A.; EL-HARAM, M.; HORNER, M. A critical review of reductionist approaches for assessing the progress towards sustainability. Environmental Impact Assessment, v.28, n.4-5, p.286311, 2008. https://doi.org/10.1016/j.eiar.2007.09.002

GENOVEZ, P. C. Território e desigualdades: análise espacial intra-urbana no estudo da dinâmica de exclusão/inclusão social no espaço urbano em São José dos Campos-SP. Dissertação (Mestrado em Sensoriamento Remoto) - INPE, São José dos Campos, 2002.

HUANG, IVY B.; KEISLER, J.; LINKOV, I. Multi-criteria decision analysis in environmental sciences: ten years of applications and trends. Science of the Total Environment, v. 409, n. 19, p.3578-3594, 2011. Disponível em: www.elsevi e r.com/locate/scitotenv. https://doi.org/10.1016/j.scitotenv.2011.06.022

IBGE - Instituto Brasileiro de Geografia e Estatística. Base de Informações do Censo Demográfico 2010: Resultados do universo por setor censitário. Rio de Janeiro, 2011.

IMPERATRIZ. Lei Ordinária № 1.069/03, de 5 de junho de 2003. Dispõe sobre a zoneamento, parcelamento, uso e ocupação do solo de Imperatriz.

JOERIN, F.; THÉRIAULT, M.; MUSY, A. Using GIS and outranking multicriteria analysis for land-use suitability assessment. International Journal of Geographical Information Science, v. 15, n. 2, p.153174, 2001. https://doi.org/10.1080/13658810051030487

KAMP, I. van; LEIDELMEIJER, G. M.; HOLLANDER, A. Urban environmental quality and human wellbeing: towards a conceptual framework and demarcation of concepts; a literature study. Landescape and Urban Planning, v.65, p. 5-18, 2003. https://doi.org/10.1016/S0169-2046(02)00232-3

KIKER, G. A. et al. Integrated Environmental Assessment and Management. Integrated Environmental Assessment and Management, v. 1, n. 2, p. 95-108, 2005. https://doi.org/10.1897/IEAM 2004a-015.1

LANG, S., BLASCHKE, T. Análise da paisagem com SIG. São Paulo: Oficina de Textos, 2009.

LOGHIN, V.; MURTOREANU, G. The determination of the urban environment quality in Romania's capital by satellite image analysis. In: CONGRESSO OF INTERNATIONAL SOCIETY FOR PHOTOGRAMMETRIC AND REMOTE SENSING, 35., 2017. Disponível em: https://www.isprs.org/proceedings/XXXV/congress/comm7/papers/161.pdf. Acesso em: 15 set. 2019.

MALCZEWSKI, J. GIS-based multicriteria decision analysis: A survey of the literature. International Journal of Geographical Information Science, v. 20, n. 7, p. 703-726, 2006. https://doi.org/10.1080/13658810600661508

MAZETTO, F. A. P de. Qualidade de vida, qualidade ambiental e meio ambiente urbano: breve comparação de conceitos. Revista Sociedade \& Natureza, v. 12, n. 24, p. 21-31, 2000.

MENDOZA, G. A.; MARTINS, H. Multi-criteria decision analysis in natural resource management: A critical review of methods and new modelling paradigms. Forest Ecology and Management, v. 230, n. 1-3, p. 1-22, 2006. https://doi.org/10.1016/.j.foreco.2006.03.023

MINAKI, C.; AMORIM, M. C. C. T. de. Espaços urbanos e qualidade ambiental - um enfoque da paisagem. Revista Formação, v. 1, n.14, p. 67-82, 2007.

MCGARIGAL, K.; MARKS, B. J. Spatial pattern analysis program for quantifying landscape structure. Gen. Tech. Rep. PNW-GTR-351. US Department of Agriculture, Forest Service, Pacific Northwest 
Research Sta-tion, p. 1-122, 1995. https://doi.org/10.2737/PNW-GTR-351

NAHAS, M. I. P. Indicadores Intra-urbanos como Instrumentos de Gestão da Qualidade de Vida Urbana em Grandes Cidades: Uma Discussão Teórica-Metodológica. In: VITTE, C. C. S. de; KEINERT, T. M. M. (org.). Qualidade de vida planejamento e gestão urbana: Discussões teóricometodológicas. Rio de Janeiro: Editora Bertrand Brasil, 2009. p. 123-153.

$\mathrm{NUCCl}$, J. C. Metodologia para determinação da qualidade ambiental urbana. Revista do Departamento de Geografia, n. 12, p. 209-224, 1998. https://doi.org/10.7154/RDG.1998.0012.0009

NUCCI, J. C.; CAVALHEIRO, F. Cobertura vegetal em áreas urbanas - conceitos e métodos. Revista GEOUSP, n. 6, p. 29-36, 1999.

NUCCI, J. C. Qualidade ambiental e adensamento urbano. São Paulo: Humanitas/ FAPESP, 2001. $236 \mathrm{p}$.

$\mathrm{NUCCI}$, J. C. Qualidade ambiental e adensamento urbano: um estudo de ecologia e planejamento da paisagem aplicado ao distrito de Santa Cecília (MSP). 2. ed. Curitiba: O Autor, 2008. 150 p.

$\mathrm{NUCCI}$, J. C. Planejamento da paisagem como subsídio para a participação popular no desenvolvimento urbano - Estudo aplicado ao bairro de Santa Felicidade - Curitiba/PR. LABS/DGEOG ed. Curitiba: [s.n.], 2010.

OLIVEIRA, H. M. Verticalização urbana e segregação socioespacial em Imperatriz - MA: uma abordagem a partir dos bairros Jardim Três Poderes e Maranhão Novo. Dissertação (Mestrado em Geografia) - Universidade Federal do Tocantins, Porto Nacional, 2017.

OVSIANNIKOVA, T. Y.; NIKOLAENKO, M. N. Quality assessment of urban environment. Materials Science and Engineering, v. 71, p. 1-7, 2015. https://doi.org/10.1088/1757-899X/71/1/012051

PANTOJA, V. M. L.; PEREIRA, J. M. Discursos do desenvolvimento: (in) Visibilidade do social, modernidade e progresso em Imperatriz, MA. INTERAÇÕES, v. 20, p. 79-93, 2019. https://doi.org/10.20435/inter.v0i0.1812

(in) Visibilidade do social, modernidade e progresso em Imperatriz, MA. INTERAÇÕES, v. 20, p. 7993, 2019.

RODRIGUES, C. Qualidade ambiental urbana: como avaliar? Revista do Departamento de Geografia, n. 11, 1997. https://doi.org/10.7154/RDG.1997.0011.0011

SANTOS, A. P.; ROCHA, S. F.; ABREU, M. V. S.; CALIJURI, M. L.; SANTOS, P. M. O uso da análise multicritério no mapeamento da fragilidade social da área urbanizada do município de Viçosa-MG. Revista Brasileira de Cartografia, v. 64, n. 5, p. 635-643, 2012.

SANTOS, R. L.; NUNES, F. G. Imperatriz do Maranhão: proposição para a compreensão do processo de ocupação e consolidação da cidade. GEOTEXTOS (ONLINE), v. 14, p. 117-141, 2018. https://doi.org/10.9771/geo.v14i2.26988

SANTOS, T. G.; VENTORINI, S. E. Análise multicritério: modelos de interesse ambiental e de áreas propícias à expansão urbana na bacia do córrego do lenheiro. Caminhos de Geografia, v.18, n. 64, p. 60-77, 2017. https://doi.org/10.14393/RCG186406

SCHMIDT, E. et al. Método para o mapeamento da qualidade ambiental urbana. In: SIMPÓSIO BRASILEIRO DE GEOGRAFIA FÍSICA APLICADA, 11., 2005, São Paulo. Anais... São Paulo: Universidade de São Paulo, 5 a 9 de setembro de 2005. p. 393-404.

SOUSA. J. M. de. Enredos da Dinâmica Urbano-regional Sulmaranhense: Reflexões a partir da centralidade econômica de Açailândia, Balsas e Imperatriz. Tese (Doutorado em Geografia) Universidade Federal de Uberlândia, Uberlândia, 2015.

VALASKI, S. Estrutura e dinâmica da paisagem: Subsídios para a participação popular no 
desenvolvimento urbano do município de Curitiba-PR. Tese (Doutorado em Geografia) Universidade Federal do Paraná, Curitiba, 2013.

VICENTE, L. E.; PEREZ FILHO, A. Abordagem sistêmica e Geografia. Geografia, v. 28, n. 3, p. 323344, 2003.

TONETTI, E. Potencialidades de adensamento populacional por verticalização das edificações e qualidade ambiental urbana no município de Paranaguá, Paraná, Brasil. Tese (Doutorado em Geografia) - Universidade Federal do Paraná, Curitiba, 2011.

TONETTI, E. L.; NUCCI, J. C.; JORGE, F. V. Qualidade ambiental da área urbana de Paranaguá, Pr. Ateliê Geográfico, v. 12, n. 3, p. 212-234, 2018. https://doi.org/10.5216/ag.v12i3.41629

TUCCI, C. E. M. Águas urbanas. Estudos Avançados, v. 22, n. 63, p. 97-112, 2008. https://doi.org/10.1590/S0103-40142008000200007

WALLENIUS, J. et al. Multiple Criteria Decision Making, Multiattribute Utility Theory: Recent Accomplishments and What Lies Ahead. Management Science, v. 54, n. 7, p. 1336-1349, 2008. https://doi.org/10.1287/mnsc. 1070.0838

WECKOWICZ, T. E. Ludwig von Bertalanffy (1901-1972): A Pioneer of General Systems Theory. Research Associate, Center for Systems Research, University of Alberta 5-21 Tory, Edmonton AB, Canada T6G 2H4; CSR3@UALTAMTS.

Recebido em: 03/10/2019

Aceito para publicação em: 28/09/2020 